Rel at i onshi $p$ bet ween var i ous chem cal treat ments on the mechani cal, anti-felting and dyeing properties of wool

\begin{tabular}{|l|l|}
\hline 著者 & Mbr i Nasukuni, Nat sudai r a M t suo \\
\hline $\begin{array}{l}\text { j our nal or } \\
\text { publ i cat i on t i t l e }\end{array}$ & Advanced Nat er i al s Resear ch \\
\hline vol une & 441 \\
\hline page $r$ ange & $376-381$ \\
\hline year & 2012- 01- 01 \\
\hline URL & ht t p: //hdl . handl e. net /2297/30351 \\
\hline
\end{tabular}




\title{
Relationship between Various Chemical Treatments on the Mechanical, Anti-felting and Dyeing Properties of Wool
}

\author{
Masukuni Mori ${ }^{1 . a}$ and Mitsuo Matsudaira $2 . b$ \\ ${ }^{1}$ Mori Consultant Engineering Office, Kaimei, Ichinomiya City, 494-0001, Japan \\ ${ }^{2}$ Kanazawa University, Kakuma-machi, Kanazawa City, 920-1192, Japan, \\ amasukuni@msc.biglobe.ne.jp, ${ }^{\mathrm{b}}$ matsudai@ed.kanazawa-u.ac.jp
}

Keywords: Anti-felting, Wool, Wet chlorination, Mechanical properties, Dyeing intensity, Eco process

\begin{abstract}
Wool has more strong points than a synthetic fiber in respect of a high elastic modulus, the outstanding thermal retaining property, hygroscopic and flame retardant property, etc. However, the only disadvantage of wool is felting in home laundering. Although various anti-felting treatments to reduce the felting behavior have been developed and used industrially, there are still problems such as environmental concerns and changes in fabric handling. In this paper, the effect of DCCA, $\mathrm{NaOCl}$ and Plasma treatment on anti-felting property ,fabric handling, yellowing, color intensity and hydrophilic property were investigated. It is concluded that $\mathrm{NaOCl}$ method is the best treatment in the point of anti-felting, fabric handling, yellowing, color intensity and environmental concerns.
\end{abstract}

\section{Introduction}

Mechanism of felting and anti-felting of wool fibers was summarized by Makinson [1] in 1979. Three anti-felting methods are used practically now for wool woven ( including knitted) fabrics. The most popular way is treatment with reacting polymer [2]. The second method; that is, Kroy-Hercosett treatment [3] is used for wool top and wool fabrics. The third wet chlorination method [4] is known as the most basic anti-felting treatment now. Reacting ether polymer is used for the polymer treatment and mixing padding method with dispersion polyurethane is the basis of the treatment. Full machine washable wool is achieved easily by cross-linking of the resin. However, a lot of binding of fibers and crossing-over points in the woven fabrics occur by the resin, and it is said that elasticity of wool fabrics decreases and the fabrics become hard. Therefore, the essential superior points of wool is loses by this method. On the other hand, a large quantity of chlorine and strong acid is used in Kroy-Hercosett treatment, ni which wool fibers are damaged violently and the environmental problem of dischargeing chlorine at high concentrations is serious. The third wet chlorination method is a batch system and optimum quantity of reagents are used and absorbed on fibers. Therefore, no reagents remain in the discharged water and is safe. However, process control is difficult because of the low temperature treatment and the results have low reproducibility, and the method is not used frequently. We think that this method is the best way to keep the superior property of wool fibers.

In this research, various properties such as fabric handling, dyeing property, surface change, yellowing and vapor absorption are studied for 8 improved wet chlorination methods of anti-felting treatment such as Permonosulfate method (Dylan), potassium permanganate method (Neva-shrink), enzyme treatment and plasma treatment $[5,6]$, etc.

\section{Experimental}

\subsection{Material}

Two kinds of samples were prepared. The sample $M$ was 2/2-twill fabric made of $1 / 40$ Merino wool $(100 \%)$ yarn in warp and weft and weight $94 \mathrm{~g} / \mathrm{m}^{2}$. The sample $\mathrm{C}$ was plain weave made of $1 / 30 \mathrm{New}$ Zealand Corriedale wool (100\%) yarn in warp and weft and $134 \mathrm{~g} / \mathrm{m}^{2}$. Standard clear finishing was done without milling and raising.For anti-felting measurements, original warp and weft threads are prepared in order to avoid the influence of relaxation shrinkage with textiles, or the finishing methods.

\subsection{Details of various kinds of physicochemical anti-felting methods}

\subsubsection{DCCA Treatment}

$20 \sim 25$ degree $\mathrm{C}$ water is put into a bath with liquor ratio $1: 20 \sim 30 . \quad 1 \mathrm{cc} / 1$ nonionic surfactant is added into the bath as a penetrating agent. Then, put the sample into the bath and stir the water until the sample becomes thoroughly and uniformly wet. $3 \%$ o.w.f (active chlorine conversion)DCCA (dichlorocyanuric acid) and $5 \%$ o.w.f sodium pyrophosphate $\left(\mathrm{Na}_{4} \mathrm{P}_{2} \mathrm{O}_{7} \cdot 10 \mathrm{H}_{2} \mathrm{O}\right)$ are put in the bath for 5 minutes. Add acetic acid to adjust $\mathrm{pH}$ between $5.5-6.0$, then temperature is raised to 35 degree $\mathrm{C}$ in 10 minutes, and the processing is continued for $50 \mathrm{~min}$. After the temperature is kept constant for $20 \mathrm{~min}$. 
$6.0 \%$ o.w.f sodium hydrogen sulfite $\left(\mathrm{NaHSO}_{3}\right)$ is added, and the temperature is raised to 60 degree $\mathrm{C}$. After 10 min continuation, the sample is washed well and the processing is completed.

\subsubsection{NaOCl}

40 degree $\mathrm{C}$ water is put into a bath with liquor ratio 1:20 30. $1 \mathrm{cc} / 1$ nonionic surfactant is added into the bath as a penetrating agent. Then, put the sample into the bath and stir the water until the sample becomes thoroughly and uniformly wet. $5 \%$ o.w.f sodium acetate is added into it as a $\mathrm{pH}$ slide agent. After stirring for $5 \mathrm{~min}, 3.0 \%$ o.w.f $\mathrm{NaOCl}$ is added, then temperature is raised to 100 degree $\mathrm{C}$ in $30 \mathrm{~min}$. After 5 min continuation, the sample is cooled and washed completely.

\subsection{3 $\mathrm{KHSO}_{5}$ treatment}

$20 \sim 25$ degree $\mathrm{C}$ water is put into a dyeing bath with liquor ratio 1:20 30. 1cc/1 nonionic surfactant is added into the bath as a penetrating agent. Then, put the sample into the bath and stir the water until the sample becomes thoroughly and uniformly wet. After putting in $6.0 \%$ o.w.f, Caroat $\left(\mathrm{KHSO}_{5}\right)$ adjust $\mathrm{pH}$ between $3.5-4.0$ by acetic acid for 30-40 min treatment at the temperature. Water of $20 \sim 25$ degree $\mathrm{C}$ is put into the bath after drainage, and 5\% o.w.f sodium sulfite is added. The water is adjusted to $\mathrm{pH} 8.0$ by 1$2 \%$ o.w.f. sodium carbonate. 30min continuation, the sample is washed well and the processing is completed.

\subsection{4 $\mathrm{KMnO}_{4}$ treatment}

$20 \sim 25$ degree $\mathrm{C}$ water is put into a dyeing bath with liquor ratio 1:20 30. $1 \mathrm{cc} / 1$ nonionic surfactant is added into the as a penetrating agent. Then, put the sample into the math and stir the water until the sample becomes wet thoroughly and uniformly. $6.0 \%$ o.w.f potassium permanganate $\left(\mathrm{KMnO}_{4}\right)$ is dissolved gradually into the water, temperature is raised to 45 degree $\mathrm{C}$ by $10 \mathrm{~min}$. The sample is treated for $40 \mathrm{~min}$ at the temperature and $10 \%$ o.w.f sodium sulfite and $10 \%$ (80\%concentration) o.w.f formic acid are added to this bath. After ascertaining that $20 \mathrm{~min}$ treatment is carried out at 40 degree $\mathrm{C}$, and the dark brown color of potassium permanganate quenching occurred completely, the sample is fully washed with cold water and processing is completed.

\subsubsection{Ar-Plasma treatment}

Plasma reactor used was a type DSSO-422 (Daia Sinku Co., Ltd.). The discharge frequency was fixed at 13.56 MHz. The plasma treatment was carried out by the following procedures. First, the fiber sample is put into the reactor, which is then evacuated at 0.001 Torr $(0.13 \mathrm{pa})$, and then argon (Ar) gas is fed into it at a flow rate of $10 \mathrm{~mL} / \mathrm{min}$. The electric power for plasma discharge is fixed at $100 \mathrm{~W}$. The internal pressure of the reactor is maintained at 0.1 Torr (13.3 pa) during plasma-treatment time of $300 \mathrm{~s}$.

\subsubsection{EDA, Enzyme and Resin treatment}

EDA (Ethylendiamine) treatment is 20 min processing at 60 degree $\mathrm{C}$ by $5 \%$ o.w.f and $\mathrm{pH} 8.0$. The treatment is completed by soaping and drying.

Enzyme (Protease) treatment is a circulation at 55 degree $\mathrm{C}$ with the $4 \mathrm{~g} / 1$ enzyme solution of for 1 hour, after deactivated and washed, dried and the processing is completed.

PU resin treatment is completed by pad-dry-curing at 130 degree $\mathrm{C}$ by the product made from Daiichi Kougyou Seiyaku, and 5 \% solution of Superflex E-2000 (Dispersion type Polyester resin).

\subsection{Experiments of anti-felting effect of treated wool yarns}

Aachen felt-ball method, IWTO-20-69 (E) [7] was employed for evaluating the felt shrinkage of wool fibers. The testing machine equipped with a cylindrical vessel, which contains $1 \mathrm{~g}$ of wool sample and 50 $\mathrm{mL}$ of distilled water was rotated three-dimensionally at a speed of $150 \mathrm{rpm}$. After $60 \mathrm{~min}$ had passed, the sample was taken out from the vessel, dried on the filter paper in the ambient air for $48 \mathrm{~h}$, and the diameter of felt ball was measured. The degree of felt shrinkage, S (\%) was defined by

$$
\mathrm{S}(\%)=\frac{\left(d_{r 0}-d\right)}{d_{r 0}} \times 100
$$

where $d$ is the felt ball diameter for either untreated or plasma treated wool sample and $d_{r 0}$ is the reference value of felt ball diameter obtained by rotating the untreated sample in the vessel for 1 min at $150 \mathrm{rpm}$. Here, it was assumed that at this condition no felting of wool fibers would be generated. After measuring the felt-ball diameter, the samples were subjected to measurement of XPS spectra. These samples were denoted as "samples after washing".

\subsection{Evaluation of fabric handle of Plasma- treated wool fabrics by KES}

Changes of mechanical properties and fabric handle was inspected by objective evaluation method [8] using KES-system for chlorinated, other physicochemical pretreated and untreated wool fabric. 


\subsection{Observation of surface morphology}

3D profile microscope (Keyence KK 9800) was used on the direct magnification of 1000 at a plane special resolution of $0.13 \mu \mathrm{m}$ and with the repetition accuracy of $0.02 \mu \mathrm{m}$

\subsection{Color measurement}

Color of samples were measured by spectro-colorimetry Minolta CM-3600D. Power source was D65, visual angel; $10^{\circ}$, sample size was $5 \mathrm{~cm} \times 5 \mathrm{~cm}$. Dyeing yield was measured from reflection ratio at the maximum absorption wavelength and $\mathrm{K} / \mathrm{S}$ was calculated using Kubelka-Munk equation. $\mathrm{L}^{*}, \mathrm{a}^{*}, \mathrm{~b}^{*}$ on CIELAB system are obtained for the dyed samples and $\mathrm{L}^{*}$ was used for the reference value of dyeing yield. Reflectance treated wool was measured and L* was calculated according to Kubelka-Munk equation. The yellowing index was obtained from the change to the untreated wool fiber.

\subsection{Hydrophilic property}

Measured according to Byreck method in JIS-1907 water-absorbency test.

\section{Result and Discussion}

\subsection{Anti-felting effect of various treated wool yarns}

Anti-felting effect is the most important verification item in this paper. Results of anti-felting property of wool fibers treated by different 8 physicochemical processing are shown in Fig.1. Anti-felting property was evaluated by IWTO Felt-ball test and showed quite low level; less than $8 \%$, for the sample treated by DCCA, $\mathrm{NaOCl}$ and Plasma for both Merino and Corriedale wool fibers. Shrink-proofing nature was low for all the other treatments including these 3 treatments.

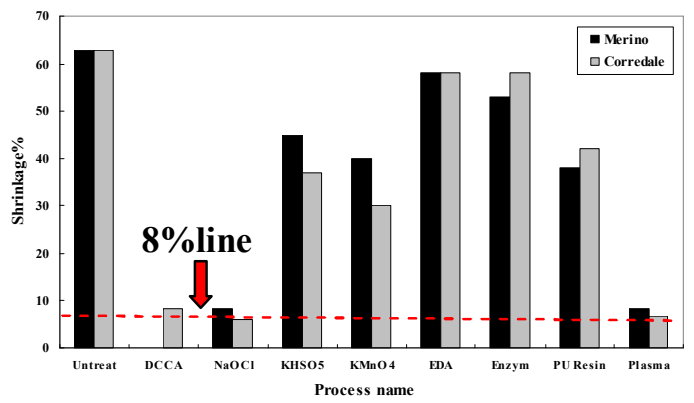

Figure 1 Comparison of anti-felting property of wool fibers treated by 8 physicochemical processing.

\subsection{Comparison of KES parameters which show fabric handle of the treated textiles}

Main KES parameters of the wool fabrics treated by different 8 anti-felting processing are shown in Fig. 2. These parameters are WT (work of tensile property), 2HB(bending hysteresis), G (shearing stiffness),2HG5 (shearing hysteresis at shear angle 5 degree),WC (compressional energy), MIU (mean frictional coefficient) SMD (surfacce roughness), and primary hand; KOSHI (stiffness). KOSHI was calculated from the objective evaluation equation $\mathrm{KN}-101 \mathrm{~W}[9,10]$

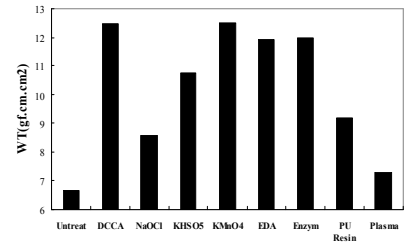

(a)

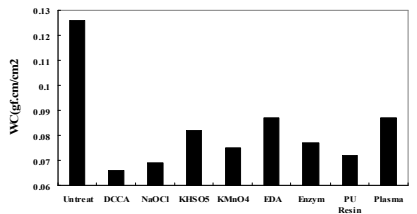

(e)

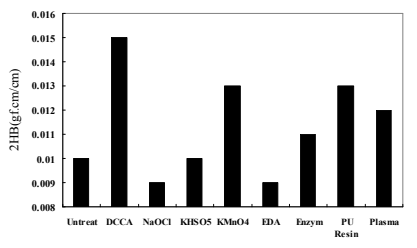

(b)

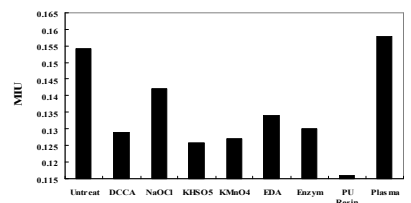

(f)

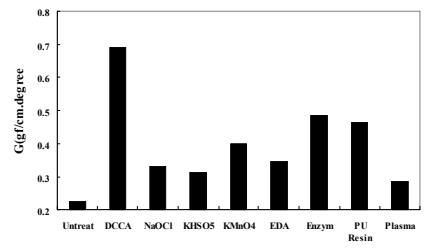

(c)

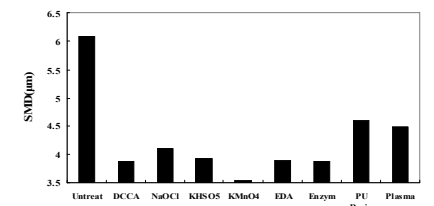

(g)

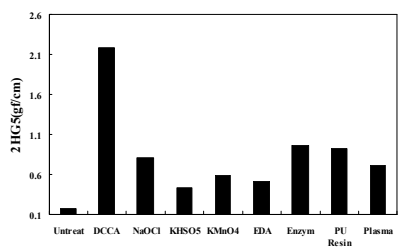

(d)

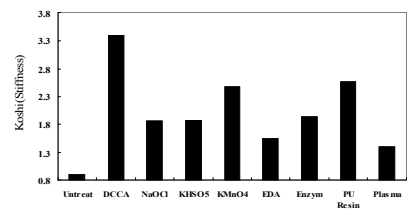

(h)

Figure 2 Effect of Anti-felting treatment on KES parameters.

It is clear that KES parameters changed much depending on the kind of anti-felting treatment. Here we want to discuss mainly about the features of DCCA, $\mathrm{NaOCl}$ and Plasma treatment. If WT $\left(\mathrm{gf} \cdot \mathrm{cm} / \mathrm{cm}^{2}\right)$ is larger, it means that the fabric is stretchable and shows high extensibility. The value was large in the case of chemical treatment because of shrinking, however, it was small for Untreated (original) and Plasma. If $2 \mathrm{HB}(\mathrm{gf} \cdot \mathrm{cm} / \mathrm{cm})$ is larger, it means that the fabric is difficult of recovery from bending deformation. 
DCCA showed the largest bending hysteresis and might be easy to occur wrinkles on the fabric. The value of $\mathrm{NaOCl}$ was the smallest and smaller than Untreated fabric. Bending stiffness (B) showed the similar tendency as $2 \mathrm{HB}$. G (gf/cm/degree) means shearing stiffness and the fabric becomes easy to occur wrinkles. The result of DCCA was large and those of $\mathrm{NaOCl}$ and Plasma were small. If $2 \mathrm{HG} 5(\mathrm{gf} / \mathrm{cm})$ is larger, it means that the fabric is difficult in recovery from shearing deformation at large shear angle ( $=5$ degree). The value of DCCA was large and those of $\mathrm{NaOCl}$ and Plasma were small, similar tendency with the result of $\mathrm{G}$. WC $\left(\mathrm{gf} \cdot \mathrm{cm} / \mathrm{cm}^{2}\right)$ means compressional energy at lateral compression of fabric and the fabric is softer with larger value. The fabric lost the softness with all the chemical treatment except Plasma. MIU ( - ) means mean frictional coefficient of fabric and the fabric becomes harsh with larger value. Although the value of Plasma was similar to Untreated, fabric became soother by chemical treatment. SMD $(\mu \mathrm{m})$ is related to surface roughness of fabric and surface hairs. All the fabrics became more smooth than Untreat by all the treatment. In the case of primary hand calculated objectively by the equation $\mathrm{KN}-101 \mathrm{~W}$, the result of Koshi is shown in Fig.2. Koshi (stiffness) is a feeling related mainly to bending stiffness. A springy property promotes this feeling. A fabric having a compact weave density and made from springy and elastic yarn gives a high value. The values of DCCA and PU-resin were large. Although we have not showed the result of Numeri (smoothness) and Fukurami (fullness and softness) in Fig.2, they are explained as follows. Numeri means a mixed feeling coming from a combination of smooth, supple, and soft feeling. A fabric woven from a cashmere fiber gives a high value. The values of DCCA and PU-resin were large. Fukurami is a feeling coming from a combination of bulky, rich and well formed impressions. A springy property in compression and thickness, accompanied by a warm feeling, is closely related with this property. The value increased for all the treatment.

\subsection{Observation of surface morphology}

Changes of surface appearance are shown in Fig.3

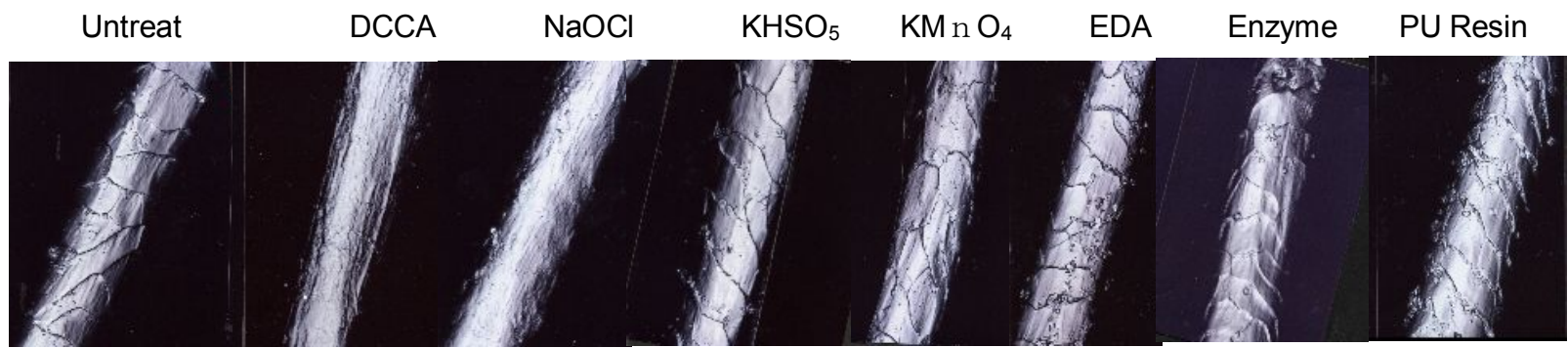

Figure 3 Surface morphology change of physicochemically treated wool fibers (1/40 merino wool).

These surface appearance was measured by 3D profile microscope KK 9800 of Keyence Co. From this figure, it is clear that wool fiber surface treated by $\mathrm{KHSO}_{5}, \mathrm{KMnO}_{4}$ and Plasma has original scales as Untreated fabric. On the other hand, wool fibers by DCCA lost their scales and looked a little thinner than the other fibers. Furthermore, streakiness is observed in the longitudinal direction of fiber. In the case of $\mathrm{NaOCl}+\mathrm{H}_{2} \mathrm{O}_{2}$, the trace of scales remain a little on the surface and there is no streakiness. It is clear that there is a close relationship between existence of scales and anti-felting effect. However, the surface of Plasma treatment is an exception.

\subsection{Color measurement}

Yellowing whiteness of 8 physicochemically treated wool fabrics are shown in Fig.4. Color intensity $(\mathrm{K} / \mathrm{S})$ for those fabrics dyed by $2.0 \%$ o.w.f Kayanol grey BL 200\% (C.I.Acid black 58) are shown in Fig.5.

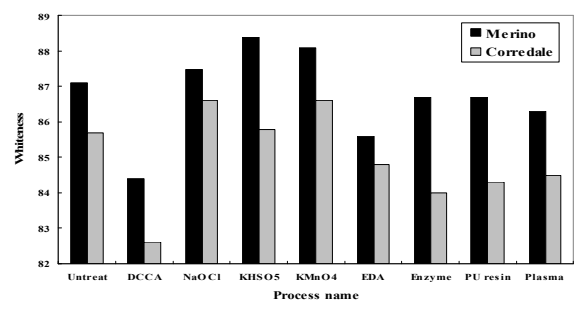

Figure 4 Whiteness comparison of 8 kinds ant-felting treatment.

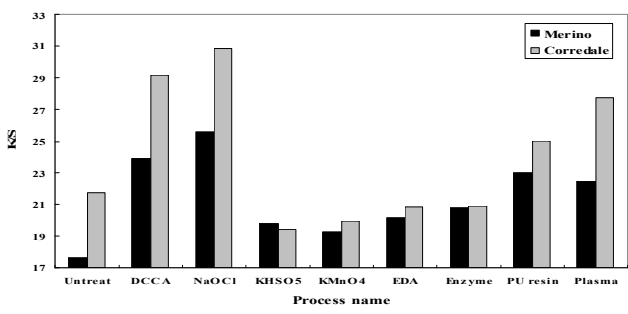

Figure 5 Color intensity comparison of 8 kinds of anti-felting treatment.

It is clear from Fig.4 that Whiteness is the smallest for DCCA treated fabric and the fabric has much 
yellowing. On the other hand, color intensity measured by K/S showed larger value for the fabrics by DCCA and $\mathrm{NaOCl}$ treated fabrics as shown in Fig.5. The color intensity was also larger for Plasma and PU-resin treated fabrics. The effect of other treatment was small and the color intensity was similar to the original untreated fabric.

\subsection{Hydrophilic property}

Hydrophilic property of wool fabrics are shown in Fig.6 for 8 kinds of anti-felting treatment. The hydrophilic property of DCCA treated fabrics increased very much compared to untreated fabric. Next comes Plasma and $\mathrm{NaOCl}$ treatment. The effect was not recognized for $\mathrm{HKSO}_{5}$ and $\mathrm{KMnO}_{4}$ treated fabrics.

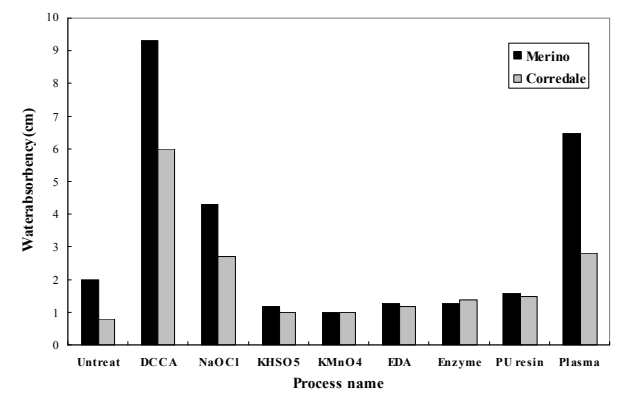

Figure 6 Water absorption height comparison by Byreck method for wool fabrics

\section{Conclusions}

Anti-felting property, fabric handling, yellowing, color intensity and hydrophilic property of wool fabrics treated by various anti-felting processing were investigated and the following conclusions were obtained.

- The effect of anti-felting was high for DCCA, $\mathrm{NaOCl}$ and

Plasma treated fabric and not enough to endure strong test such as felt-ball laundry method for other treatments.

- The changes in fabric handling, especially for bending and shearing properties, changes are great and fabric becomes hard by DCCA treatment. However, fabric is soft in the case of $\mathrm{NaOCl}$ treatment.

- Yellowing is large in the case of DCCA treatment, however, whiteness increases by $\mathrm{NaOCl}$ treatment.

- Color intensity is in the order of $\mathrm{NaOCl}>$ DCCA $>$ Plasma treatment, and the color intensity does not change in the other 5 methods.

- Hydrophilic property is in the order of DCCA.> Plasma $>\mathrm{NaOCl}$, and is similar to that of untreated fabric for the other 5 methods.

There is a close inter-relationship between anti-felting, color intensity and hydrophilicity. If there is little anti-felting, then color intensity is also low. Yellowing of the fabric by DCCA is extremely large and fabric handling is poor compared with the other 2 methods ( $\mathrm{NaOCl}$, Plasma), and therefore, it is difficult to use DCCA method practically.

In conclusion, $\mathrm{NaOCl}$ method is best from the point of new of anti-felting, fabric handling, yellowing and color intensity. To avoid environmental problems, we can apply $\mathrm{NaOCl}+\mathrm{H}_{2} \mathrm{O}_{2}$ improved method. This paper is a fundamental research work to obtain the optimum method of anti-felting of wool fabrics.

\section{Reference:}

[1] KR Makinson,Wool Shrinkproofing(New York:Marcel Dekker,(1979)

[2] D Allanach,KRF Cockett and D.N Lewis,BP 1571188

[3] D Feldman,JR McPhee and WV Moran,Textile Mfr,93(1967)122

[4] J Lewis,Wool Sci.Rew.,55(1978)23

[5]M.mori and N.Inagaki,Textile Research Journal79-6 (2006) 687-694

[6]M.Mori and N.Inagaki, Research Journal of Textile and apparel,10,(2006) 33-45

[7] IWTO-20-69,Method for the determination of the Felting Properties of loose wool and Top(Prepared by the Sub-committee for Test methods and Values and adopted by I.W.T.O Technical Committee)

[8] The Textile Machinery Society of Japan(1998)" Manufacturing Performance and Mechanical Properties of Fabric".p15-29, Amagasaki -insatsu,Osaka

[9] S. Kawabata:"The Standardization and Analysis of Hand Evaluation, 2nd Ed.", HESC, Text. Mach. Soc. Japan, p.28 (1980)

[10]M.Mori,M,Matsudaira and N.Inagaki Journal of Textile Engineering 52 (2006) 19-27 


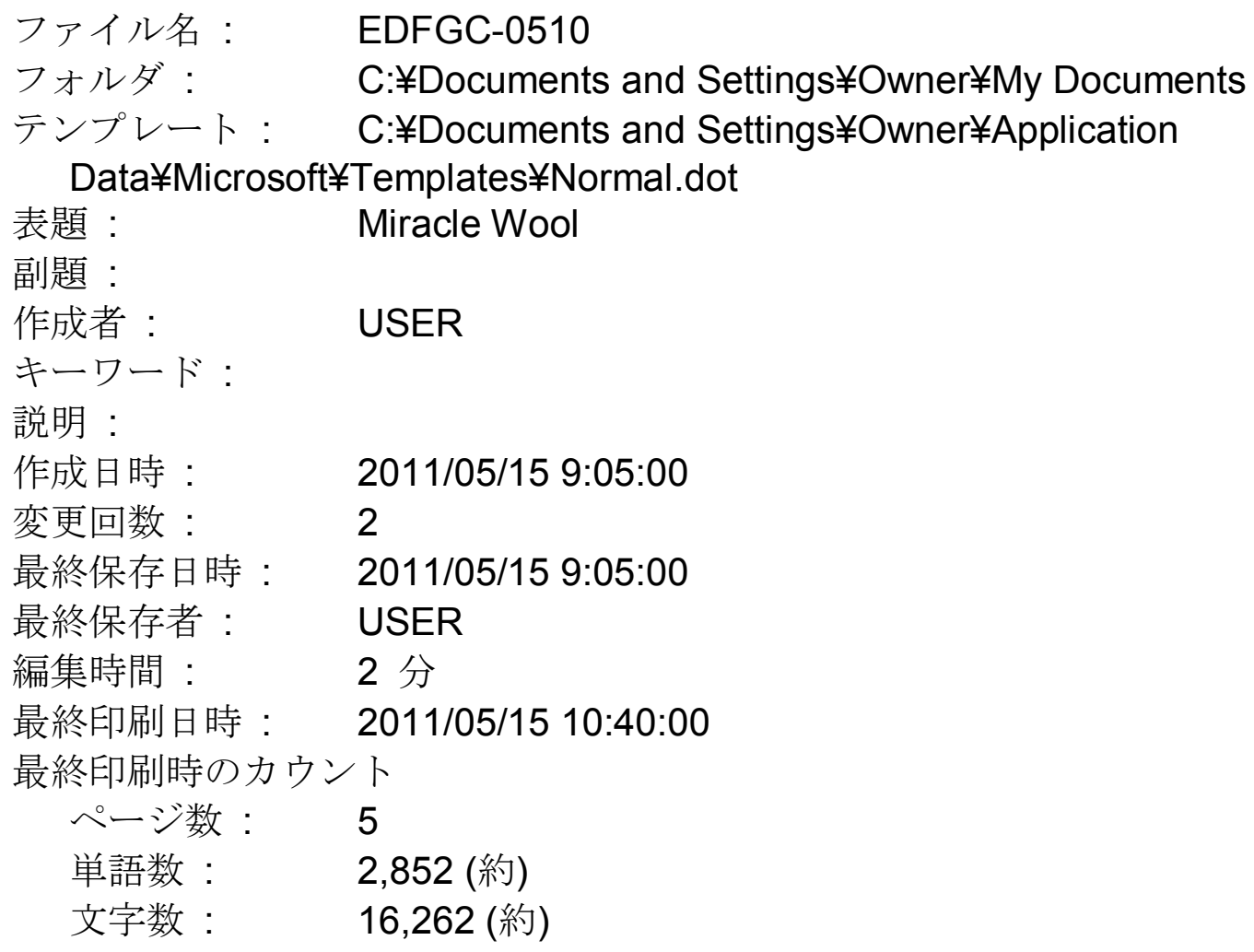

